\title{
Unidimensional Analysis of Oil Velocity Fields in Lubricant Film in Effective Lubrication of a Sliding Journal Bearing
}

\author{
Piotr RYBACKI* Zenon GRZEŚ
}

\begin{abstract}
In order to provide effective lubrication in a sliding journal bearing unidimensional analysis was conducted to investigate oil flow velocity in the lubricant film formed in the gap between the shaft journal and the sleeve. An original equation was developed using FEM to determine fluid velocity depending on the angular velocity of journal $\omega$ and the width of gap $h$, which in turn is determined by the value of transverse journal load and the displacement of its geometrical centre in relation to the sleeve centre $e$. Mathematical models were developed, which were subjected to simulation studies in order to verify their logical accuracy. Results facilitate a more precise and rapid selection of work parameters for transversely loaded sliding bearings. Moreover, these results may be used in further multi-criterion analyses of lubrication parameters for sliding bearings during their operation.
\end{abstract}

Keywords: FEM; fluid mechanics; lubricant film; sliding bearing

\section{INTRODUCTION}

Sliding bearings are commonly used in the design of such machines as combustion engines, pumps, compressors, generators, turbines, etc., in which kinematic joints are particularly exposed to high and dynamically changing loads. Popularity of sliding bearings results from their simple design, capacity to transfer high loads and performance characteristics. They also ensure greater vibration damping and more stable work in comparison to roller bearings. Moreover, sleeves of sliding bearings are characterised by lower hardness, since they are covered by a soft metal or plastic in order to protect journals against damage in case of a lack of lubrication, primarily at the start of the machine.

Introduction of oil between two mutually displaced faying surfaces of the journal and the sleeve results in the formation of an ultra-thin layer, referred to as oil (lubricating) film. Thanks to the presence of this layer the so-called fluid friction develops, whose coefficient is many times lower than that of Coulomb friction [1-9].

Within the last several decades sliding bearings and the mechanism of their lubrication have been analysed by many researchers. The process of formation and degradation of the lubricating film was analysed using the hydrostatic or hydrodynamic lubrication theory, whose primary objective was to determine velocity fields and pressure of oil filling the gap between the faying surfaces [10-19]. Those studies focused primarily on the assessment of the effect of bearing shape, plane of division of the journal, the number and shape of oil grooves on the lubrication mechanism. Changes in geometry of the journal and sleeve of the bearing were analysed in terms of their wear under load and the effect of these changes on actual parameters of such a kinematic pair.

Using the presently available state-of-the-art computer technologies attempts are being made to develop new methods of mathematical modelling to investigate the flow of gases or liquids and to perform its numerical simulation. For this purpose the finite element method (FEM) may be applied, which in the opinion of authors of numerous research publications is an effective, well-developed, extensively used and reliable numerical tool in the analysis of the complex geometry of solids and flow areas in liquids and gases. Following the FEM principles the analysed flow area is divided into sections, each of which is treated as a certain geometrical object, referred to as a finite element (FE). On its margins (in corners or on edges) and in selected inner points nodes are located for which the values of the investigated function are calculated. The manner in which the analysed function changes within a FE is identified using approximation functions constituting the basis, also called shape functions. Association of this function with node values of the unknown constitutes an approximate solution to that problem. Parameters of the approximation function are determined using variational methods [20-30].

\section{ANALYSIS OF VELOCITY FIELDS OF OIL FILM}

Identification of finite elements needs to be initiated by determining the velocity profile for the oil film between two cylindrical planes, formed by the stationary sleeve of a sliding bearing and the journal rotating inside it with angular velocity $\omega$.

It is known based on empirical studies and theoretical analyses that laminar flow of the lubricating oil occurs in sliding journal bearings $[1,23,26-28]$. It is connected with a relatively small Reynolds number $v_{0} h_{\max } \cdot v^{-1}$, where $v_{0}$ denotes relative rubbing speed and $h_{\max }-$ maximum gap width. Introduction of local system of coordinates $x, y$, having the following relationships with the cylindrical system $r, \vartheta, z$ :

$$
\begin{aligned}
& x=r \vartheta \approx r_{0} \vartheta, \text { where } x \in\left[0,2 \pi r_{0}\right] \\
& y=r_{\mathrm{p}}-r_{0}, \text { where } y \in[0, h] \\
& z=z^{\prime}, \text { where } z \in[-b, b]
\end{aligned}
$$

made it possible to include three unknowns of the oil film in a sliding bearing, i.e. the tangential component of the velocity vector $v_{x}=v_{x}(x, y)$, the axial component of the velocity vector $v_{z}=v_{z}(x, y)$ and pressure, considered as a two dimensional function, assuming $p=p(x, z)$ (Fig. 1).

The system of polar coordinates $r, \vartheta, z$, starts at centre $O_{\text {J }}$ of the journal, with angle $\vartheta$ measured from the straight 
line $O_{\mathrm{J}} O_{\mathrm{P}}$ passing through the centres of the journal and the sleeve. The centres of the loaded journal and the sleeve generally do not overlap, assuming their mutually eccentric position, where $\overline{O_{\mathrm{J}} O_{\mathrm{P}}}=e$. As a result of this displacement the width of the gap is a function of the angular coordinate $h=h(\vartheta)$, while radius $r$ of a point on the sleeve surface is a dependent variable

$$
\tilde{r}_{\mathrm{P}}(\vartheta)=r_{0}+h(\vartheta)
$$

where $r_{0}$ is the radius of the journal.

The journal rotates with a constant angular velocity $\omega$, which causes a specific motion of the lubricating fluid, which according to the assumption fills the entire gap, while only a portion of the oil film is under pressure. This segment is called the loaded area, with its width referred to as the oil film angle of contact for that journal [1, 4-6, 8, 23].

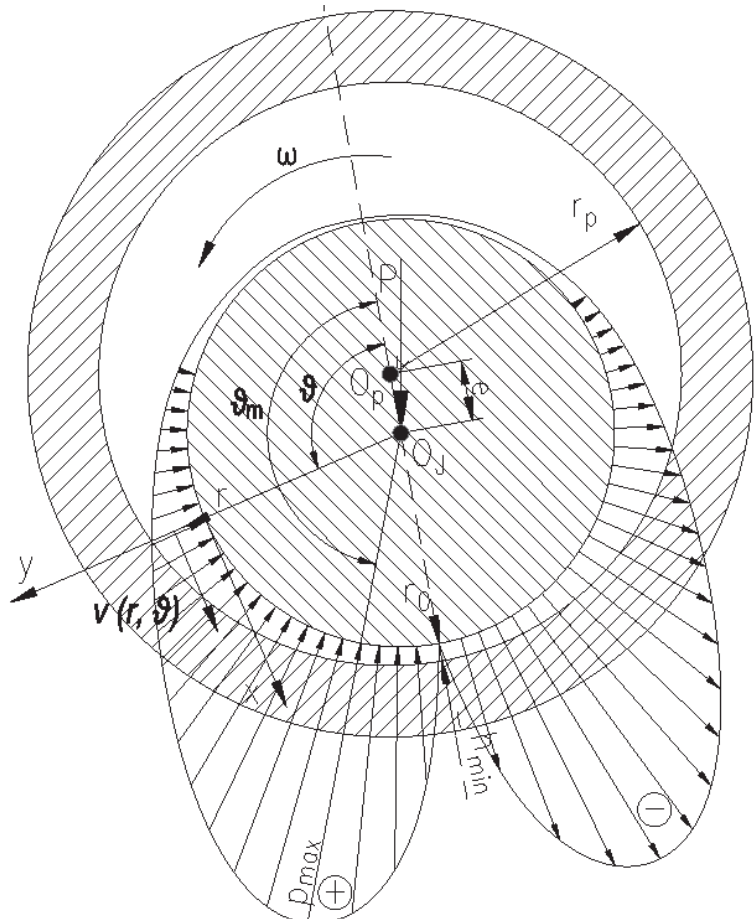

Figure 1 Pressure areas in oil film of a sliding bearing: $O_{P}$ - geometrical centre of sleeve, $O_{J}$ - geometrical centre of journal, $r_{p}$ - internal radius of sleeve $(\mathrm{mm}), b$ - sleeve width $(\mathrm{mm}), r_{0}$ - radius of journal $(\mathrm{mm}), e$ - displacement of the centre of journal and the centre of sleeve $(\mathrm{mm}), P$ - journal load $\left(\mathrm{kg} \cdot \mathrm{m} \cdot \mathrm{s}^{-2}\right), p$ - pressure of lubricating fluid $\left(\mathrm{kg} \cdot \mathrm{m}^{-1} \cdot \mathrm{s}^{-2}\right), \theta$ - angular displacement of journal (deg), $h$ - width of gap between journal surface and inner surface of sleeve $(\mathrm{mm}), \omega$ - angular velocity of journal $(1 / \mathrm{s})$

Considering the above-mentioned assumptions we may write the simplified equation of oil movement in the lubricating film

$\frac{\partial p}{\partial x}=\mu \frac{\partial^{2} v_{x}}{\partial y^{2}}, \quad \frac{\partial p}{\partial z}=\mu \frac{\partial^{2} v_{z}}{\partial y^{2}}$

and the equation of its continuity

$\frac{\partial v_{x}}{\partial x}+\frac{\partial v_{z}}{\partial z}=0$
Functions of lubricating film velocity should meet adhesion conditions on surfaces wetted with oil:

$v_{x}=v_{0}=$ const, $v_{z}=0$ for $y=0$

$v_{x}=0, v_{z}=0$ for $y=h(x)$

where: $v_{0}$ tangential velocity of journal $(\mathrm{m} / \mathrm{s}), v_{x}, v_{y}, v_{z}$ components $x, y, z$ of velocity of lubricating fluid $(\mathrm{m} \cdot \mathrm{s})$.

The FEM analyses were conducted for four fields of oil film velocity, which were identified in cutting planes at angles: $\vartheta_{\mathrm{m}}, \vartheta_{\mathrm{m}}-2 \vartheta_{0}, \vartheta_{\mathrm{m}}-\vartheta_{0}, \vartheta_{\mathrm{m}}+\vartheta_{0}$, where $\vartheta_{\mathrm{m}}$ identifies the plane for the maximum value of oil pressure in the lubricating film (Fig. 2).

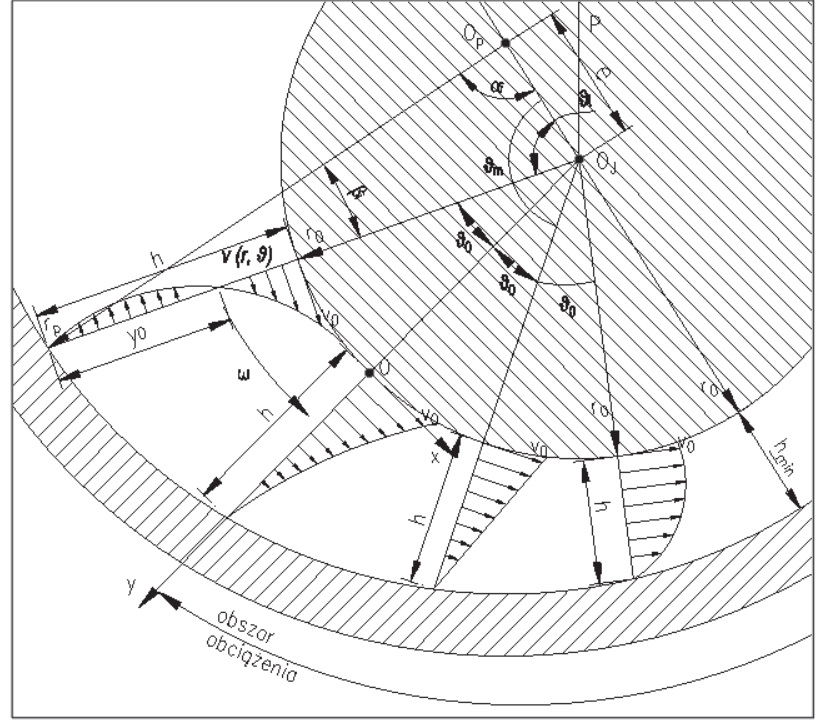

Figure 2 Velocity fields in oil film of a sliding bearing

The integration range $[0, h]$, i.e. the distance between the surfaces of the journal and the sleeve, was divided into $n$ identical segments (elements), whose length $l=h \cdot n^{-1}$ is dependent on angle $\vartheta$. The distance between the surfaces of the journal and the sleeve depending on the angle of the cutting plane was established from the equation

$h=r_{\mathrm{p}}-\left(r_{0} \cos \beta+e \cos \alpha\right)$

thus

$l=\frac{r_{\mathrm{p}}-\left(r_{0} \cos \beta+e \cos \alpha\right)}{n}$

where: $\alpha$ - angle between $r_{\mathrm{p}}$ and $e(\mathrm{deg}), \beta$ - angle between $r_{\mathrm{p}}$ and $r_{0}(\mathrm{deg})$.

Ends of segments determine $k$ points, which are referred to as nodes and denoted successively from 1 to $k$, while $k=n+1$. In each internal node there is an unknown value of flow velocity, which is generally called the node value of the investigated function of velocity. The boundary conditions were assumed to be values of velocity for extreme nodes, i.e. $v_{n}=0$ and $v_{0}=\omega r_{0}$.

FEM assumes the application of the approximating function $\Phi(x)$ of velocity $v(x)$ within a given finite element (FE), which is a function of shape (the so-called base 
function), assuming the value of 1 at one node and 0 at the other nodes. In turn, the values of functions approximating shape $\Phi(x)$ in extreme nodes depend on the pre-defined boundary conditions [20-25].

The profile of velocity at any given section $\vartheta$ is typically curvilinear and depends on the sign of the derivative $\frac{\partial p}{\partial \vartheta}[1,8,15,23]$. An exception in this respect is found for angle $\vartheta_{\mathrm{m}}$, where this profile is linearly variable, for which $\frac{\partial p}{\partial \vartheta_{\mathrm{m}}}=0$ (Fig. 3). Thus, node values of velocity, considering the adopted boundary conditions, may be determined from the equation

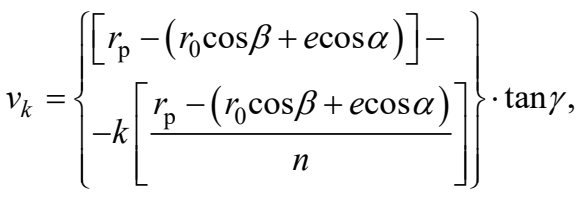

knowing that

$\tan \gamma=\frac{v_{0}}{r_{\mathrm{p}}-\left(r_{0} \cos \beta+e \cos \alpha\right)}$, where: $n$ - the number of segments in the integration range, $k$ - the number of the node.

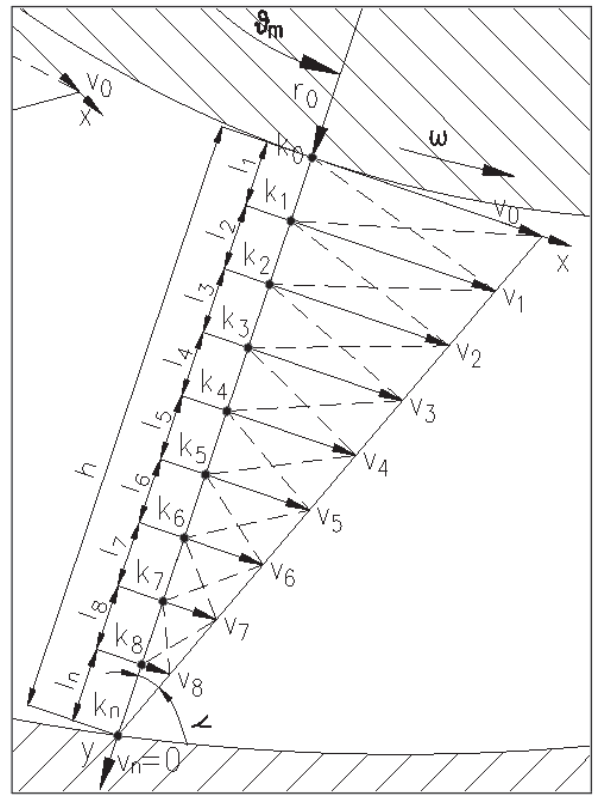

Figure 3 The resultant profile of the oil velocity field in the lubricating film of a sliding journal bearing for angle $\vartheta_{\mathrm{m}}$, where $\frac{\partial p}{\partial \vartheta_{\mathrm{m}}}=0$

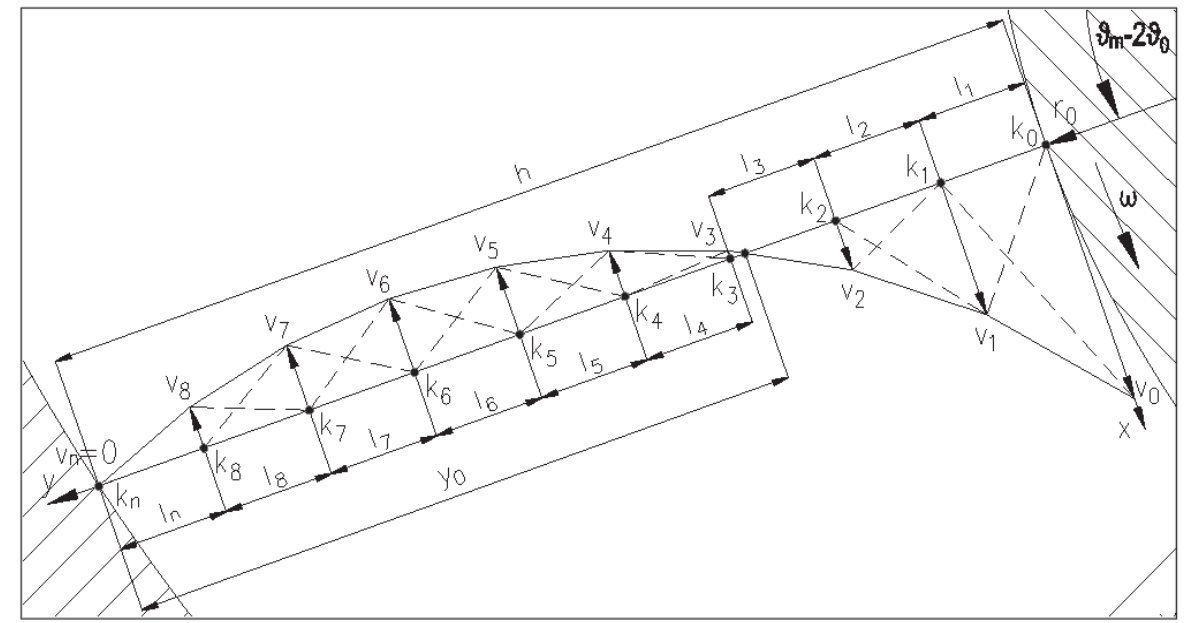

a)

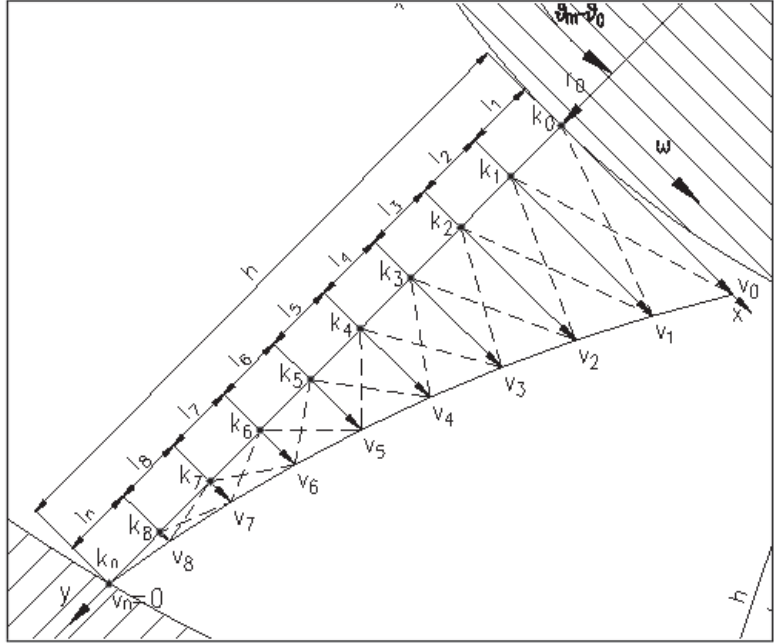

b)

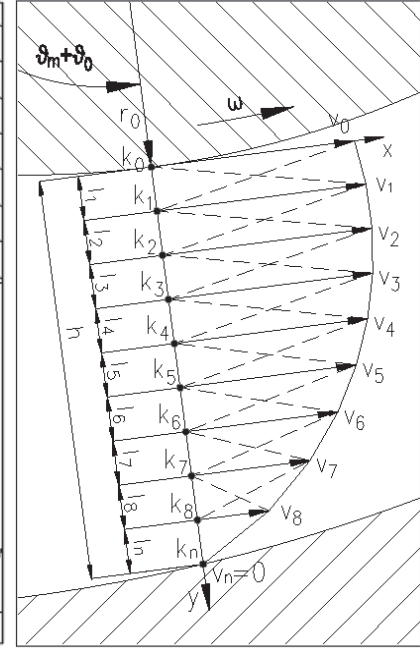

Figure 4 Resultant profiles of oil film velocity in a sliding journal bearing for $\frac{\partial p}{\partial \vartheta} \neq 0$, where: a) $\vartheta=\vartheta_{\mathrm{m}}-2 \vartheta_{0}$, b) $\vartheta=\vartheta_{m}-\vartheta_{0}$, c) $\vartheta=\vartheta_{\mathrm{m}}+\vartheta_{0}$ 
In the other profiles we have dependence $\frac{\partial p}{\partial \vartheta} \neq 0$, thus the velocity fields are curvilinear and they were analysed using FEM (Fig. 4). The construction of functions and equations to determine node velocities was started from the profile for angle $\vartheta=\vartheta_{\mathrm{m}}+\vartheta_{0}$. In turn, for angle $\vartheta=\vartheta_{\mathrm{m}}-\vartheta_{0}$ the inverse function was used, determining the shape of the velocity field for angle $\vartheta=\vartheta_{\mathrm{m}}+\vartheta_{0}$ in relation to the straight line described by the equation

$u=\frac{v_{0}}{\sin \gamma}$

In accordance with the FEM computational procedure for angle $\vartheta=\vartheta_{m}+\vartheta_{0}$ the function approximating the solution was assumed as a linear combination of function $x$ and $(1-x)$ for $x \in[0,1]$ according to equation $\bar{v}_{n}=v_{n+1} x+v_{n}(1-x)$ for $x \in[0,1]$

In order to obtain a global solution for the entire oil film velocity field with the plotted FE grid for angle $\vartheta=\vartheta_{\mathrm{m}}+\vartheta_{0}$ Eq. (12) was used, which was transcribed in local systems of coordinates starting at nodes:

$$
\begin{aligned}
& \frac{100 \bar{v} \mu}{\left[\frac{r_{\mathrm{p}}-\left(r_{0} \cos \beta+e \cos \alpha\right)}{n} \sum_{e=1}^{E} \int_{0}^{1} \frac{\mathrm{d} \bar{v}}{\mathrm{~d} x} \frac{\mathrm{d} \delta \bar{v}}{\mathrm{~d} x} \mathrm{~d} x=\right.} \\
& =v_{0} c\left(\sin \vartheta_{\mathrm{m}}+\sin \vartheta\right)\left[\frac{r_{\mathrm{p}}-\left(r_{0} \cos \beta+e \cos \alpha\right)}{n}\right] \sum_{e=1}^{E} \int_{0}^{1} \delta \bar{v} \mathrm{~d} x,
\end{aligned}
$$

where: $E$ number of finite elements, $\mu$ absolute viscosity of oil $\left(\mathrm{kg} \cdot \mathrm{m}^{-1} \cdot \mathrm{s}^{-1}\right), \bar{v} \quad$ value of disturbances in laminar flow velocity caused by transverse vibrations of sliding bearing $(\mathrm{m} / \mathrm{s})$

Substituting Eq. (11) we obtain

$$
\begin{aligned}
& \frac{100 \bar{v} \mu}{\left[\frac{r_{\mathrm{p}}-\left(r_{0} \cos \beta+e \cos \alpha\right)}{n} \int_{0}^{1}\left[\frac{\mathrm{d}}{\mathrm{d} x}\left(v_{n+1} x+v_{n}(1-x)\right) \frac{\mathrm{d}}{\mathrm{d} x}\left(\delta v_{n+1} x+\delta v_{n}(1-x)\right)\right] \mathrm{d} x=\right.} \\
& =v_{0} c\left(\sin \vartheta_{\mathrm{m}}+\sin \vartheta\right)\left[\frac{r_{p}-\left(r_{0} \cos \beta+e \cos \alpha\right)}{n}\right] \int_{0}^{1}\left\{\delta\left[v_{n+1} x+v_{n}(1-x)\right]\right\} \mathrm{d} x
\end{aligned}
$$

where after integration the following form was obtained

$$
\begin{aligned}
& 100 \bar{v} \mu\left[\frac{r_{\mathrm{p}}-\left(r_{0} \cos \beta+e \cos \alpha\right)}{n}\right]^{-1}\left[v_{n} \delta v_{n}+\left(v_{n+1}-v_{n}\right)\left(\delta v_{n+1}-\delta v_{n}\right)=\right. \\
& =v_{0} c\left(\sin \vartheta_{m}+\sin \vartheta\right)\left[\frac{r_{p}-\left(r_{0} \cos \beta+e \cos \alpha\right)}{n}\right]\left(\delta v_{n}+\delta v_{n+1}\right) .
\end{aligned}
$$

Since variations $\delta v_{i}$ are mutually independent an expanded system of equations is formed, in which the number of unknowns is dependent on the number of FE.
For a single FE given in Fig. 5 the distribution of velocity between nodes $k_{n}$ and $k_{n+1}$, may be written in the matrix form:

$$
\frac{100 \bar{v} \mu}{v_{0} c\left(\sin \vartheta_{\mathrm{m}}+\sin \vartheta\right)\left[\frac{r_{p}-\left(r_{0} \cos \beta+e \cos \alpha\right)}{n}\right]^{2}}\left[\begin{array}{cc}
1 & -1 \\
-1 & 1
\end{array}\right]\left[\begin{array}{c}
v_{n} \\
v_{n+1}
\end{array}\right]=\left[\begin{array}{l}
0,5 \\
0,5
\end{array}\right]
$$

where

$c=\frac{\Delta p}{\Delta z}=$ const.

The solution to matrix (15) makes it possible to derive equations and determine boundary values of the investigated function defining the shape of the lubricating film velocity field for angle $\vartheta=\vartheta_{\mathrm{m}}+\vartheta_{0}$. The number of equations providing a solution is dependent on the accuracy of the grid and the number of $\mathrm{FE}$ in the investigated field.

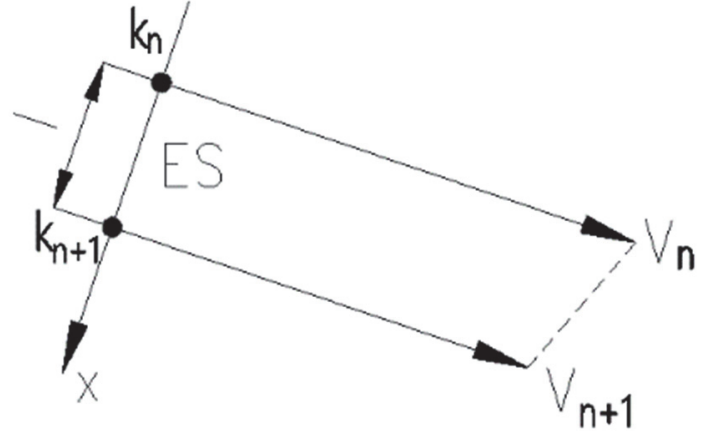

Figure $5 \mathrm{~A}$ scheme of a finite element 


\section{VERIFICATION OF THE MODEL AND SIMULATION TESTS}

The model developed using FEM was verified by analysing a sliding bearing with the inner sleeve diameter of $60000 \mathrm{~mm}$ and outer journal diameter of $59.705 \mathrm{~mm}$. The distance between the surfaces of the journal and the sleeve was divided into 9 identical segments (elements), whose length is $l=0.111$, $h=0.111\left[r_{\mathrm{p}}-\left(r_{0} \cos \beta+e \cos \alpha\right)\right]$. Ends of the segments determining 10 nodes were denoted successively from 0 to 9.

Applying Eq. (12) for the adopted boundary conditions, i.e. $v_{9}=0$ and $v_{0}=\omega r_{0}$ we obtain

$$
\begin{aligned}
& 100 \bar{v} \mu\left(\sin \vartheta_{\mathrm{m}}+\sin \vartheta\right)\left\{0.111\left[r_{\mathrm{p}}-\left(r_{0} \cos \beta+e \cos \alpha\right)\right]\right\}^{-1} \int_{0}^{1}\left\{\left[\frac{\mathrm{d}}{\mathrm{d} x}\left(v_{1} x\right) \frac{\mathrm{d}}{\mathrm{d} x}\left(\delta v_{1} x\right)\right]+\right. \\
& +\left[\frac{\mathrm{d}}{\mathrm{d} x}\left(v_{2} x+v_{1}(1-x)\right) \frac{\mathrm{d}}{\mathrm{d} x}\left(\delta v_{2} x+\delta v_{1}(1-x)\right)\right]+\left[\frac{\mathrm{d}}{\mathrm{d} x}\left(v_{3} x+v_{2}(1-x)\right) \frac{\mathrm{d}}{\mathrm{d} x}\left(\delta v_{3} x+\delta v_{2}(1-x)\right)\right]+ \\
& +\left[\frac{\mathrm{d}}{\mathrm{d} x}\left(v_{4} x+v_{3}(1-x)\right) \frac{\mathrm{d}}{\mathrm{d} x}\left(\delta v_{4} x+\delta v_{3}(1-x)\right)\right]+\left[\frac{\mathrm{d}}{\mathrm{d} x}\left(v_{5} x+v_{4}(1-x)\right) \frac{\mathrm{d}}{\mathrm{d} x}\left(\delta v_{5} x+\delta v_{4}(1-x)\right)\right]+ \\
& +\left[\frac{\mathrm{d}}{\mathrm{d} x}\left(v_{6} x+v_{5}(1-x)\right) \frac{\mathrm{d}}{\mathrm{d} x}\left(\delta v_{6} x+\delta v_{5}(1-x)\right)\right]+\left[\frac{\mathrm{d}}{\mathrm{d} x}\left(v_{7} x+v_{6}(1-x)\right) \frac{\mathrm{d}}{\mathrm{d} x}\left(\delta v_{7} x+\delta v_{6}(1-x)\right)\right]+ \\
& \left.+\left[\frac{\mathrm{d}}{\mathrm{d} x}\left(v_{8} x+v_{7}(1-x)\right) \frac{\mathrm{d}}{\mathrm{d} x}\left(\delta v_{8} x+\delta v_{7}(1-x)\right)\right]+\left[\frac{\mathrm{d}}{\mathrm{d} x}\left(v_{8}(1-x)\right) \frac{\mathrm{d}}{\mathrm{d} x}\left(\delta v_{8}(1-x)\right)\right]\right\} \mathrm{d} x= \\
& =0,111 v_{0} c\left(\sin \vartheta_{\mathrm{m}}+\sin \vartheta\right)\left[r_{p}-\left(r_{0} \cos \beta+e \cos \alpha\right)\right] \int_{0}^{1}\left\{\delta\left[v_{0} x\right]+\delta\left[v_{1} x\right]+\delta\left[v_{2} x+v_{1}(1-x)\right]+\right. \\
& +\delta\left[v_{3} x+v_{2}(1-x)\right]++\delta\left[v_{4} x+v_{3}(1-x)\right]+\delta\left[v_{5} x+v_{4}(1-x)\right]+\delta\left[v_{6} x+v_{5}(1-x)\right]+ \\
& \left.+\delta\left[v_{7} x+v_{6}(1-x)\right]+\delta\left[v_{8} x+v_{7}(1-x)\right]+\delta\left[v_{8}(1-x)\right]\right\} \mathrm{d} x .
\end{aligned}
$$

After integration we obtain

$$
\begin{aligned}
& 100 \bar{v} \mu\left\{0,111\left[r_{p}-\left(r_{0} \cos \beta+e \cos \alpha\right)\right]\right\}^{-1}\left[\left(v_{2}-v_{1}\right)\left(\delta v_{2}-\delta v_{1}\right)+\left(v_{3}-v_{2}\right)\left(\delta v_{3}-\delta v_{2}\right)+\right. \\
& +\left(v_{4}-v_{3}\right)\left(\delta v_{4}-\delta v_{3}\right)+\left(v_{5}-v_{4}\right)\left(\delta v_{5}-\delta v_{4}\right)+\left(v_{6}-v_{5}\right)\left(\delta v_{6}-\delta v_{5}\right)+\left(v_{7}-v_{6}\right)\left(\delta v_{7}-\delta v_{6}\right)+ \\
& +\left(v_{8}-v_{7}\right)\left(\delta v_{8}-\delta v_{7}\right)=0,111 v_{0} c\left(\sin \vartheta_{\mathrm{m}}+\sin \vartheta\right)\left[r_{p}-\left(r_{0} \cos \beta+e \cos \alpha\right)\right]\left[\delta v_{1}+\delta v_{2}+\delta v_{3}+\right. \\
& \left.+\delta v_{4}+\delta v_{5}+\delta v_{6}+\delta v_{7}+\delta v_{8}\right] .
\end{aligned}
$$

Where after ordering

$$
\begin{aligned}
& \frac{100 \bar{v} \mu}{v_{0} c\left(\sin \vartheta_{\mathrm{m}}+\sin \vartheta\right)\left\{0,111\left[r_{p}-\left(r_{0} \cos \beta+e \cos \alpha\right)\right]\right\}^{2}}\left[\left(v_{1}-v_{2}\right) \delta v_{1}+\left(-v_{1}+2 v_{2}-v_{3}\right) \delta v_{2}+\right. \\
& +\left(-v_{2}+2 v_{3}-v_{4}\right) \delta v_{3}+\left(-v_{3}+2 v_{4}-v_{5}\right) \delta v_{4}+\left(-v_{4}+2 v_{5}-v_{6}\right) \delta v_{5}+\left(-v_{5}+2 v_{6}-v_{7}\right) \delta v_{6}+ \\
& \left.+\left(-v_{6}+2 v_{7}-v_{8}\right) \delta v_{7}+\left(-v_{7}+2 v_{8}\right) \delta v_{8}\right]=\delta v_{1}+\delta v_{2}+\delta v_{3}+\delta v_{4}+\delta v_{5}+\delta v_{6}+\delta v_{7}+\delta v_{8} .
\end{aligned}
$$

Assuming that variations $\delta v_{i}$ are mutually independent an expanded system of nine equations is formed, written in a matrix form:

$$
\frac{100 \bar{v} \mu}{v_{0} c\left(\sin \vartheta_{\mathrm{m}}+\sin \vartheta\right)\left\{0.111\left[r_{\mathrm{p}}-\left(r_{0} \cos \beta+e \cos \alpha\right)\right]^{2}\right.}\left[\begin{array}{cccccccc}
1 & -1 & 0 & 0 & 0 & 0 & 0 & 0 \\
-1 & 2 & -1 & 0 & 0 & 0 & 0 & 0 \\
0 & -1 & 2 & -1 & 0 & 0 & 0 & 0 \\
0 & 0 & -1 & 2 & -1 & 0 & 0 & 0 \\
0 & 0 & 0 & -1 & 2 & -1 & 0 & 0 \\
0 & 0 & 0 & 0 & -1 & 2 & -1 & 0 \\
0 & 0 & 0 & 0 & 0 & -1 & 2 & -1 \\
0 & 0 & 0 & 0 & 0 & 0 & -1 & 2
\end{array}\right]\left[\begin{array}{c}
v_{1} \\
v_{2} \\
v_{3} \\
v_{4} \\
v_{5} \\
v_{6} \\
v_{7} \\
v_{8}
\end{array}\right]=\left[\begin{array}{c}
0,5 \\
1 \\
1 \\
1 \\
1 \\
1 \\
1 \\
1
\end{array}\right]
$$


After matrix (20) was solved and considering that $v_{0}=$ $\omega r_{0}$ we obtain

$v_{1}=\frac{32 \omega r_{0} c\left(\sin \vartheta_{\mathrm{m}}+\sin \vartheta\right)\left\{0.111\left[r_{\mathrm{p}}-\left(r_{0} \cos \beta+e \cos \alpha\right)\right]\right\}^{2}}{100 \bar{v} \mu}$,

$v_{2}=\frac{31.5 \omega r_{0} c\left(\sin \vartheta_{\mathrm{m}}+\sin \vartheta\right)\left\{0.111\left[r_{\mathrm{p}}-\left(r_{0} \cos \beta+e \cos \alpha\right)\right]\right\}^{2}}{100 \bar{v} \mu}$

$v_{3}=\frac{30 \omega r_{0} c\left(\sin \vartheta_{\mathrm{m}}+\sin \vartheta\right)\left\{0.111\left[r_{\mathrm{p}}-\left(r_{0} \cos \beta+e \cos \alpha\right)\right]\right\}^{2}}{100 \bar{v} \mu}$,

$v_{4}=\frac{27.5 \omega r_{0} c\left(\sin \vartheta_{\mathrm{m}}+\sin \vartheta\right)\left\{0.111\left[r_{\mathrm{p}}-\left(r_{0} \cos \beta+e \cos \alpha\right)\right]\right\}^{2}}{100 \bar{v} \mu}$,

$v_{5}=\frac{24 \omega r_{0} c\left(\sin \vartheta_{\mathrm{m}}+\sin \vartheta\right)\left\{0.111\left[r_{\mathrm{p}}-\left(r_{0} \cos \beta+e \cos \alpha\right)\right]\right\}^{2}}{100 \bar{v} \mu}$

$v_{6}=\frac{19.5 \omega r_{0} c\left(\sin \vartheta_{\mathrm{m}}+\sin \vartheta\right)\left\{0.111\left[r_{\mathrm{p}}-\left(r_{0} \cos \beta+e \cos \alpha\right)\right]\right\}^{2}}{100 \bar{v} \mu}$,

$v_{7}=\frac{14 \omega r_{0} c\left(\sin \vartheta_{\mathrm{m}}+\sin \vartheta\right)\left\{0.111\left[r_{\mathrm{p}}-\left(r_{0} \cos \beta+e \cos \alpha\right)\right]\right\}^{2}}{100 \bar{v} \mu}$,

$v_{8}=\frac{7.5 \omega r_{0} c\left(\sin \vartheta_{\mathrm{m}}+\sin \vartheta\right)\left\{0.111\left[r_{\mathrm{p}}-\left(r_{0} \cos \beta+e \cos \alpha\right)\right]\right\}^{2}}{100 \bar{v} \mu}$.
Based on Eqs. (21) to (28) values of oil film velocity were determined at nodes of the adopted grid at the section at angle $\vartheta=\vartheta_{\mathrm{m}}+\vartheta_{0}$. Simulation studies were conducted for eleven velocities $v_{0}\left(\mathrm{~m} \cdot \mathrm{s}^{-1}\right)$, with the following values: $0.050,0.055,0.060,0.065,0.070,0.075,0.080,0.085$, $0.090,0.095$ and 0100 . In this analysis the value of disturbance velocity was assumed at $\bar{v}=0.01(\mathrm{~m} / \mathrm{s})$, which results from journal vibrations. Absolute viscosity of the tested engine lubricant is $\mu=0.319\left(\mathrm{~kg} \cdot \mathrm{m}^{-1} \cdot \mathrm{s}^{-1}\right)$, at $c=40$ $\left(\mathrm{kg} \cdot \mathrm{m}^{-2} \cdot \mathrm{s}^{-2}\right)$.

Fig. 6 presents values of individual velocities of the oil film found in the sliding journal bearing adopted for the simulation studies using Eq. (8) developed for angle $\vartheta_{\mathrm{m}}$, where $\frac{\partial p}{\partial \vartheta_{\mathrm{m}}}=0$. For all the conducted simulation studies shapes of the functions reflect the assumptions adopted for the constructed model. Individual straight lines determined based on the values of angular velocity of journal $\omega$ for the sliding journal bearing determine shapes of oil velocity fields in the lubricating film in relation to the horizontal axis for the adopted FE grid.

Fig. 7 presents node velocities at the section for angle $\vartheta=\vartheta_{\mathrm{m}}+\vartheta_{0}$, which were determined based on Eqs. (21) to (28). Shapes of functions and thus determined velocity fields confirm logical accuracy of the developed models. The greatest value of velocity was recorded at node $k_{1}$, followed by its non-linear reduction to 0 at point $k_{9}$.

Results of simulation studies at the section for angle $\vartheta$ $=\vartheta_{\mathrm{m}}-\vartheta_{0}$, where node velocities were calculated from inverse Eqs. (21) to (28) in relation to the straight line of dependence (10), are presented in Fig. 8. The course of the function for each initial velocity $v_{0}$ reflects the FE grid. The established velocities decrease non-linearly reaching negative values at nodes $k_{7}$ and $k_{8}$, which shows a return oil flow in the lubricating film of the analysed bearing.

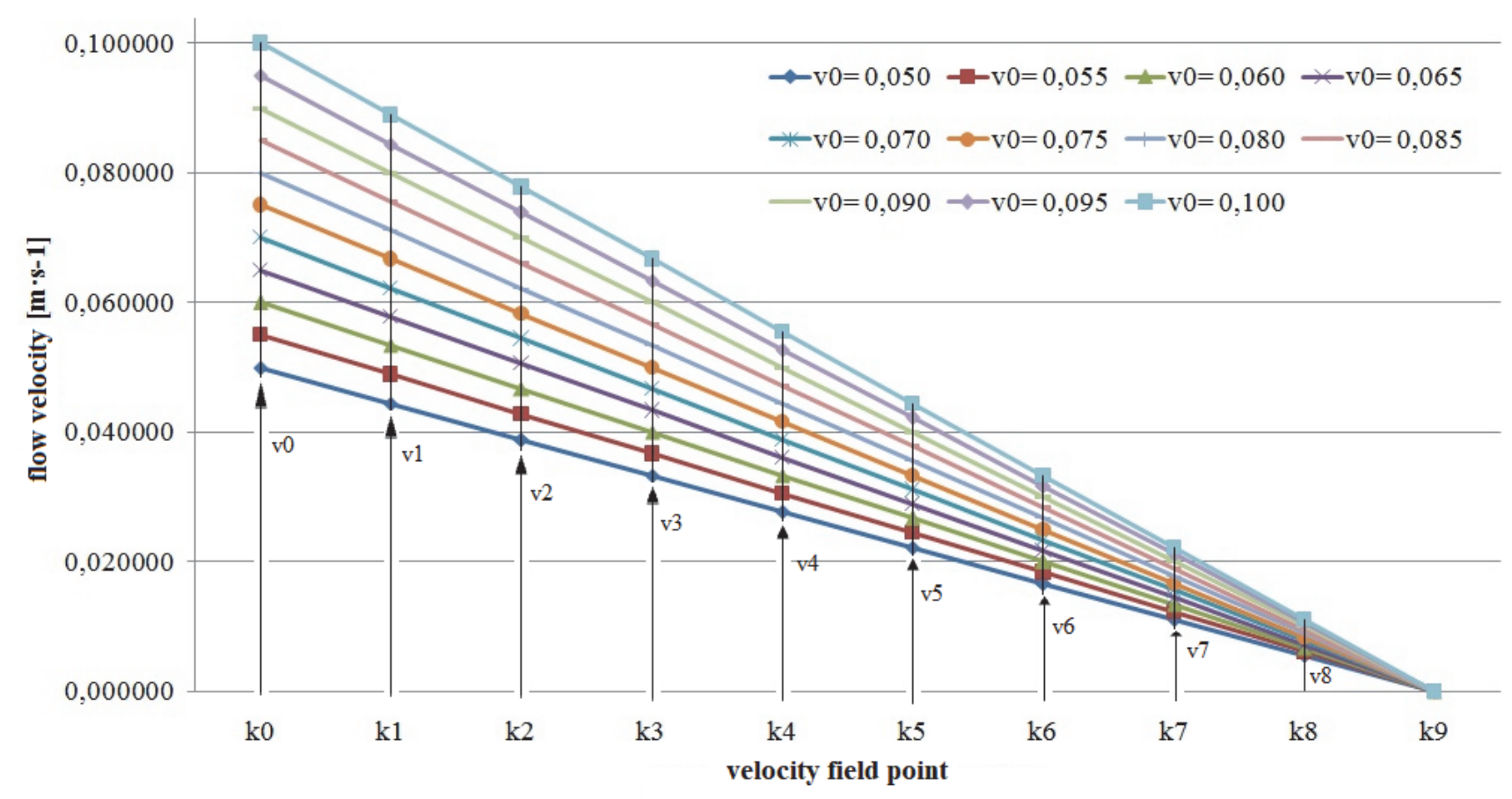

Figure 6 Oil velocity in the lubricating film of a sliding journal bearing $\left(r_{\mathrm{p}}=60000 \mathrm{~mm}, r_{\mathrm{o}}=59.705 \mathrm{~mm}, n=9, \alpha=22.750^{\circ}, \beta=0.059^{\circ}, \vartheta=\vartheta_{\mathrm{m}}=110.0^{\circ}\right)$ 


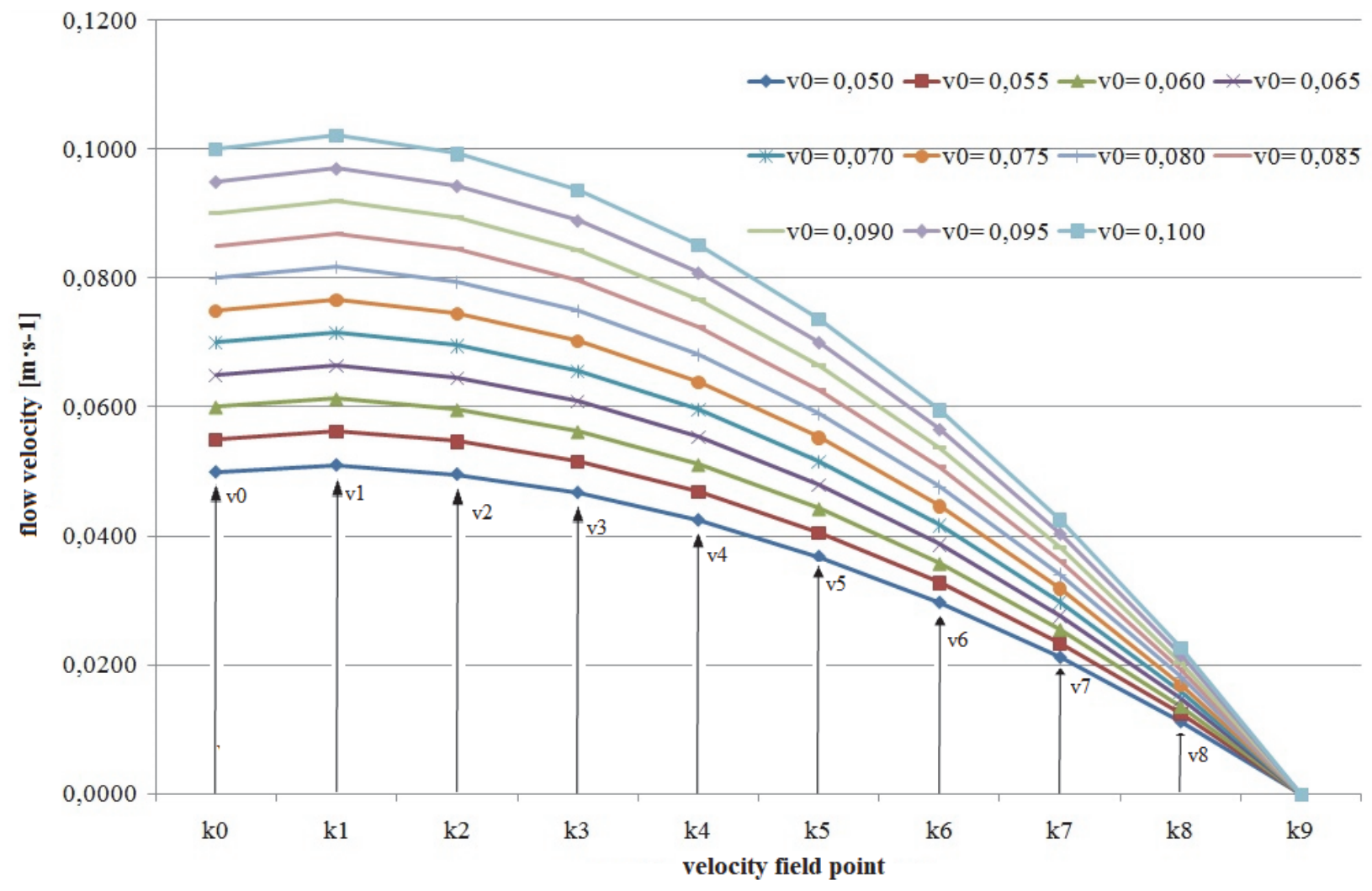

Figure 7 Oil velocity in the lubricating film of a sliding journal bearing

$\left(r_{p}=60000 \mathrm{~mm}, r_{o}=59.705 \mathrm{~mm}, \bar{v}=0.01 \mathrm{~m} / \mathrm{s}, n=9, c=40\left(\mathrm{~kg} \cdot \mathrm{m}^{-2} \cdot \mathrm{s}^{-2}\right), \alpha=2.750^{\circ}, \beta=0.001^{\circ}, \vartheta=\vartheta_{\mathrm{m}}+\vartheta_{0}=120.0^{\circ}\right)$

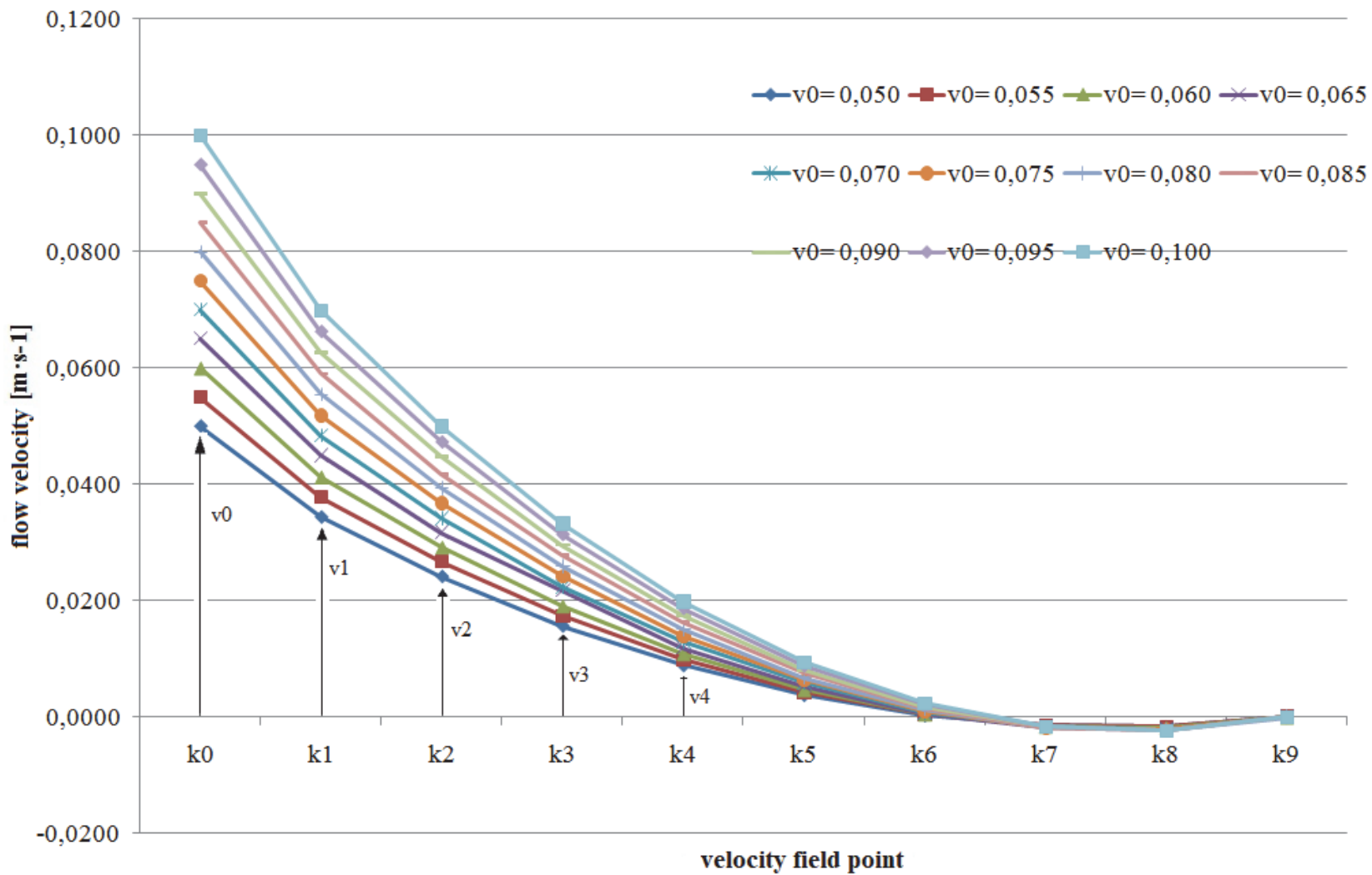

Figure 8 Oil velocity in the lubricating film of a sliding journal bearing $\left(r_{p}=60000 \mathrm{~mm}, r_{\mathrm{o}}=59.705 \mathrm{~mm}, \bar{v}=0.01 \mathrm{~m} \cdot \mathrm{s}^{-1}, n=9, c=40 \mathrm{~kg} \cdot \mathrm{m}^{-2} \cdot \mathrm{s}^{-2}, \alpha=48.410^{\circ}, \beta=12.610^{\circ}, \vartheta=\vartheta_{\mathrm{m}}-\vartheta_{0}=100.0^{\circ}\right)$

\section{CONCLUDING REMARKS}

This study presents the application of FEM to solve an engineering problem in order to construct a computational model and to analyse oil velocity fields in the lubricating film of a journal bearing at a constant rotational velocity of the journal. Developed equations as a result of approximation of differential equations based on the theory 
of fluid hydrodynamics and subjected to the computational FEM procedure provide approximate solutions.

The developed model makes it possible to conduct simulation studies and determine the effect of changes in functional parameters of a sliding bearing on its lubrication conditions. Simulation and numerical analysis may be used to investigate the effect of load values of journal $P$ on displacements $e$ of geometrical centres $O_{\mathrm{P}}$ and $O_{\mathrm{J}}$.

From the point of view of in-service testing the proposed models may be used to assess the effect on lubrication efficiency exerted by an increase in the gap between the surfaces of the journal and the sleeve as a result of wear. An important problem is also connected with assessing the effect of an increase in rotational velocity of the journal and disturbances caused by vibrations on the quality of the lubrication process.

\section{REFERENCES}

[1] Paula, B., Ndeffoa, M., Massina, P., \& Moësd, N. (2017). An integration technique for $3 \mathrm{D}$ curved cracks and branched discontinuities within the extended Finite Element Method. Finite Elements in Analysis and Design, 123, 19-50. https://doi.org/10.1016/j.finel.2016.09.002

[2] Martin, A., Esnault, J. B., \& Massin, P. (2016). About the use of standard integration schemesfor X-FEM in solid mechanics plasticity. Comput. Methods Appl. Mech. Eng. 283, 551-572. https://doi.org/10.1016/j.cma.2014.09.028

[3] Jain, S. C., Sinhasan, R., \& Singh, D. V. (1984). A study of elastohydrodynamic lubrication of a journal bearing with piezoviscous lubricants. ASLE Trans., 5, 168-176. https://doi.org/10.1080/05698198408981558

[4] Krasowski, P. (2002). Modelling of laminar unsteady and unsymetrical oil flow in slide journal bearing gap. Tribologia, 5, 1425-1436.

[5] Krasowski, P. (2008). Pressure and capacity forces in slide journal plane bearing by laminar unsteady lubrication. Journal of Polish CIMAC, 3(2), 91-98.

[6] Krasowski, P. (2009). Prędkość przepływu oleju w szczelinie łożyska przy niestacjonarnym laminarnym smarowaniu. Gliwice: Modelowanie Inżynierskie, 38, 95102 .

[7] Kyureghyan, K. \& Piekarski, W. (2008). Analiza wyznaczenia rozkładu ciśnienia w łożysku korbowym. Eksploatacja i Niezawodność - Maintenance and Reliability. 4, 19-24.

[8] Singh, U. P., Gupta, R. S., \& Kapur, V. K. (2013). On the application of Rabinowitsch fluid model on an annular ring hydrostatic thrust bearing. Tribology International, 58, 6570. https://doi.org/10.1016/j.triboint.2012.09.014

[9] Patel, R. R., Valles, D., Riveros, G. A., Thompson, D. S., Perkins, E. J., Hoover, J. J., Peters, J. F., \& Tordesillas, A. (2018). Stress flow analysis of bio-structures using the finite element method and the flow network approach. Finite Elements in Analysis and Design, 152, 46-54. https://doi.org/10.1016/j.finel.2018.09.003

[10] Cha, M., Kuznetsov, E., \& Glavatskih, S. (2013). A comparative linear and nonlinear dynamic analysis of compliant cylindrical journal bearings. Mechanism and Machine Theory, 64, 80-92. https://doi.org/10.1016/j.mechmachtheory.2013.01.008

[11] Chasalevris, A. \& Papadopoulos, C. (2014). A novel semianalytical method for the dynamics of nonlinear rotorbearing systems. Mechanism and Machine Theory, 72, 3959. https://doi.org/10.1016/j.mechmachtheory.2013.09.014

[12] LaBouff, G. A. \& Booker, J. F. (1985). Dynamically loaded journal bearing: a finite element treatment for rigid and elastic surfaces. Journal Tribology, 107, 505-521. https://doi.org/10.1115/1.3261117

[13] Lahmar, M., Ellagoune, S., \& Bou-Said, B. (2010). Elastohydrodynamic lubrication analysis of a compliant journal bearing considering static and dynamic deformations of the bearing liner. Tribology Transaction, 53, 349-368. https://doi.org/10.1080/10402000903312356

[14] Oh, K. P. \& Huebner, K. H. (1973). Solution of elastohydrodynamic finite journal bearing problems. Journal Lubr. Tech, 95, 342-352. https://doi.org/10.1115/1.3451827

[15] Sfyris, D. \& Chasalevris, A. (2012).An exact analytical solution of the Reynolds equation for the finite journal bearing lubrication. Tribology International, 55, 46-58. https://doi.org/10.1016/j.triboint.2012.05.013

[16] Taylor, C. \& O'Callaghan, J. F. (1972). A numerical solution of the elastohydrodynamic problem using finite elements. Journal of Mechanical Engineering Science, 14, 229. https://doi.org/10.1243/JMES_JOUR_1972_014_030_02

[17] Wang, C. C. \& Chen, C. K. (2001). Bifurcation analysis of self-acting gas journal bearings. Journal of Tribology, 12(4), 755-768. https://doi.org/10.1115/1.1388302

[18] Wierzcholski, K. (1995). Mathematical methods in hydrodynamic theory of lubrication. Szczecin: Technical University Press.

[19] Yadav, S. K. \& Sharma, S. C. (2014). Performance of hydrostatic tilted thrust pad bearings of various recess shapes operating with non-Newtonian lubricant. Finite Elements in Analysis and Design, 87, 43-55. https://doi.org/10.1016/j.finel.2014.04.009

[20] Awasthia, R. K., Jainb, S. C., \& Sharmab, S. C. (2006). Finite element analysis of orifice-compensated multiple hole-entry worn hybrid journal Bering. Finite Elements in Analysis and Design, 42, 1291-1303. https://doi.org/10.1016/j.finel.2006.06.007

[21] Cook, R. D., Malkus, D. S., Plesha, M. E., \& Witt, R. J. (2002). Concepts and Applications of Finite Element Analysis. New York: Wiley.

[22] Dammak, L. \& Hadj-Taïeb, E. (2010). Finite Element Analysis of Elastohydrodynamic Cylindrical. Journal Bearing, FDMP, 6(4), 419-429.

[23] Türk, Ö., Bozkaya, C., \& Tezer-Sezgin, M. (2014).A FEM approach to biomagnetic fluid flow in multiple stenosed channels. Computers \& Fluids, 97, 40-51. https://doi.org/10.1016/i.compfluid.2014.03.021

[24] Sukumaran Nair, V. P. \& Prabhakaran Nair, K. (2004). Finite element analysis of elastohydrodynamic circular journal bearing with micropolar lubricants. Finite Elements in Analysis and Design, 41, 75-89. https://doi.org/10.1016/j.finel.2004.04.001

[25] Zhang, Z. \& Jiang, X. (1990). Analysis of Cylindrical Journal Bearing with Viscoelastic Bush. Journal of Tribology, 112, 442-446. https://doi.org/10.1115/1.2920279

[26] Zienkiewicz, O. C. \& Taylor, R. L. (2000). The Finite Element Method. Oxford: Butterworth-Heinemann.

[27] Sinhasan, R. \& Sah, P. L. (1996). Static and dynamic performance characteristics of an orifice compensated hydrostatic journal bearing with non-Newtonian lubricants. Tribology International, 29(6), 515-526. https://doi.org/10.1016/0301-679X(95)00115-K

[28] Stafford, A. C., Henshell, R. D., \& Dudley, B. R. (1978). Finite element analysis of problems in elastohydrodynamic lubrication. Proceedings of the Fifth Leeds-Lyon Symposium on Tribology, 329.

[29] Wan, L., Wang, D. Z., \& Gao, Y. Y. (2015). Investigations on the effects of different tool edge geometries in the finite element simulation of machining. Strojniski vestnik, 61, 157166. https://doi.org/10.5545/sv-jme.2014.2051

[30] Wan, L. \& Wang, D. Z. (2015). Numerical analysis of the formation of the dead metal zonewith different tools in orthogonal cutting. Simulation Modelling Practice and Theory, 56, 1-15. https://doi.org/10.1016/j.simpat.2015.04.006 


\section{Contact information:}

\section{Piotr RYBACKI}

(Corresponding author)

Department of Agronomy,

Poznań University of Life Sciences,

11 Dojazd St., 60-632 Poznań, Poland

E-mail: piotr.rybacki@up.poznan.pl

\section{Zenon GRZEŚ}

Department of Biosystems Engineering,

Poznań University of Life Sciences,

50 Wojska Polskiego St., 60-637 Poznań, Poland 